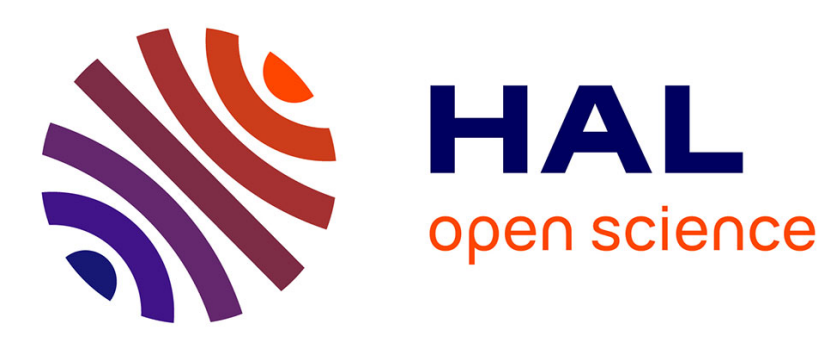

\title{
Twinning in chalcostibite revisited
}

Massimo Nespolo

\section{To cite this version:}

Massimo Nespolo. Twinning in chalcostibite revisited. European Journal of Mineralogy, 2018, 30 (5), pp.967-973. 10.1127/ejm/2018/0030-2764 . hal-01917230

\section{HAL Id: hal-01917230 \\ https://hal.univ-lorraine.fr/hal-01917230}

Submitted on 9 Nov 2018

HAL is a multi-disciplinary open access archive for the deposit and dissemination of scientific research documents, whether they are published or not. The documents may come from teaching and research institutions in France or abroad, or from public or private research centers.
L'archive ouverte pluridisciplinaire HAL, est destinée au dépôt et à la diffusion de documents scientifiques de niveau recherche, publiés ou non, émanant des établissements d'enseignement et de recherche français ou étrangers, des laboratoires publics ou privés. 


\title{
Twinning in chalcostibite revisited
}

\author{
Massimo NESPOLO \\ Université de Lorraine, CNRS, CRM2, Nancy, France. \\ Corresponding author, email massimo.nespolo@,univ-lorraine.fr \\ ORCID $\underline{\text { 0000-0003-2530-5399 }}$
}

6 Abstract: Twinning in chalcostibite has been reported to occur on the (104) plane with respect to

7 the standard setting Pnma of the space group. However, different axial settings have been used for

8 this mineral, and in the literature an axial ratio which corresponds to the Pnam setting is often

9 reported. Unfortunately, the same indexing of the twin plane, (104), is incorrectly used for both

10 settings; this has led to an incorrect reticular analysis of the twin, which could have been an

11 example of diperiodic twin, an alleged category which has no known examples to date. In this

12 article, we trace back the origin of the inconsistent indexing, we present a revised reticular analysis

13 which puts back this twin in the category of triperiodic twins, and we discuss the atomic structure at

14 the composition plane, showing that a small adjustment of the metal-sulphur coordination is

15 required to accommodate the change in orientation occurring when the twin forms.

16 Key-words: chalcostibite; crystallographic orbits; twinning.

\section{$17 \quad 1$ Introduction}

18 In our review of hybrid twins in non-silicate minerals (Nespolo and Ferraris, 2009) we have shown

19 that almost all non-Friedelian twins, i.e. twins with a twin index beyond the empirical limit of 6, are

20 hybrid twins whose effective twin index is within or close to this limit. One remarkable exception

21 remained however, which seemed to escape the reticular theory of twinning (Friedel, 1926), even in

22 its last extension as theory of hybrid twins (Nespolo \& Ferraris, 2005): (104) twin in chalcostibite

$23 \mathrm{CuSbS}_{2}$. In our analysis, we found two concurrent sublattices with twin indices 29 and 25 , leading

24 to an effective twin index of 14.5, far too large to explain this twin on the basis of the reticular 
25 theory . Chalcostibite (104) could therefore be the first example of diperiodic twin, an alleged

26 category introduced as intermediate between the usual triperiodic twins and the exceptional case of

27 monoperiodic twins discovered in Zinnwald twin of quartz (Friedel, 1933).

28 While working on the relation between diperiodic twins, of which to the best of our knowledge

29 there are no confirmed representatives to date, and plesiotwins, a type of oriented crystal association

30 based on a large coincidence site lattice (Nespolo et al., 1999), we have traced back the history of

31 that (104) twin in chalcostibite and realized that, due to a variety of axial settings adopted by

32 different authors, at a certain point an error in the indexing occurred in the literature, which remains

33 in reference textbooks. In this article, we give a brief historical perspective of this twin, show that

34 once the twin plane is correctly indexed the twin is still hybrid but with a much lower effective twin

35 index (5.5 instead of 14.5), and explain its occurrence on the basis of pseudo-eigensymmetry of the

36 crystallographic orbits occupied by $\mathrm{Cu}$ and $\mathrm{Sb}$, which is the basis of a satisfactory structural

37 restoration across the twin plane.

\section{Axial setting of chalcostibite and the problem of indexing the twin and composition plane}

40 Chalcostibite (named by Glocker, 1847, p. 32) is a sulfosalt also reported under different names:

kupferantimonglanz (Zincken, 1835); rosite (Huot, 1841, p. 197); wolfsbergite, from the type 1879).

44 Chalcostibite crystallizes in a space group of type Pnma (No. 62); both the point group ( $\mathrm{mmm}$ ) and the type of unit cell $(o P)$ are invariant under any permutation of the basis vectors. Such a permutation does result in different settings of the space group (a recent detailed treatment is available in Nespolo and Aroyo, 2016), but the structural information was not available in the old mineralogical literature. Before the discovery of X-ray diffraction, the unit cell was estimated from 
49 an axial ratio obtained by indexing the developed faces, and expressed in the form of a ratio $a: b: c$,

50 usually normalized with respect to $\boldsymbol{b}$ taken as the longest parameter; however, different orientations

51 resulted in different indexing of the faces. In case of orthorhombic crystals, the presence of

52 symmetry operations of the same order (binary rotations or mirror reflections) along the three basis

53 vectors made the indexing particularly disputable. As a result, different axial ratios were often

54 adopted by various authors. In the case of chalcostibite, the following ratios were reported:

55 - Friedel (1879): 0.7841:1:0.8220

56 - Groth (1889): 0.5231:1:0.6395

57 - Laspeyres (1891): 0.527598:1:0.618584

58 - Penfield and Frenzel (1897, 1898): 0.5312:1:0.63955 (from their own measurements);

$59 \quad 0.5283: 1: 0.6364$ (from measurement of Laspeyres, 1891); 0.5242:1:0.6377 (from

60 measurement of Friedel, 1879, and re-indexing forms $\{730\}$ and $\{370\}$ as $\{320\}$ and $\{230\}$

$61 \quad$ respectively)

62 - Goldschmidt (1923): 0.8026:1:0.6275

63 - Ungemach (1923): 0.6275:1:2.4082

64 - Palache et al. (1952): 0.4153:1:0.2606

65 The ratios reported by Groth, by Laspeyers, and by Penfield and Frenzel (GLP in the following, for

66 short) were essentially the same. The transformations are the following ${ }^{1}$ : Friedel to GLP: c,2a,b;

67 Friedel to Palache: $3 \mathbf{c}, 6 \mathbf{b},-2 \mathbf{a} ;$ GLP to Palache: $3 \mathbf{a}, 6 \mathbf{c},-\mathbf{b}$; Goldschmidt to Palache: $\mathbf{b}, 3 \mathbf{a},-\mathbf{c}$;

68 Ungemach to Palache: $\mathbf{b}, \mathbf{c}, \mathbf{a}$.

69 Cell parameters obtained from X-ray diffraction were published by Hofmann (1933), for the

70 standard setting Pnma of the space group, namely $a=6.12, b=3.89, c=14.51 \AA$, corresponding to

71 the ratio $1.5899: 1: 3.8254$, i.e. $0.4156: 0.2614: 1$, very close to Palache apart from the exchange of $\mathbf{b}$

51 Some of the transformations given by Palache et al. (1952) correspond to a change to left-handed reference.

6 In these cases, we have modified a sign to obtain a right-handed setting. 
72 and $\mathbf{c}$ basis vectors. Cell parameters from X-ray diffraction were also reported by Cervelle et al.

73 (1979) as $a=6.026, b=14.510, c=3.800 \AA$, without any indication of the space group; they

74 however clearly correspond to the Pnam setting and a ratio $0.4153: 1: 0.2619$, very close to the ratio

75 of Palache. The transformation from Hofmann to Palache is a,c,-b and from Palache to Hofmann is

$76 \mathbf{a},-\mathbf{c}, \mathbf{b}$. Finally, the transformation from GLP to Hoffman is $3 \mathbf{a}, \mathbf{b}, 6 \mathbf{c}$. In other words, the orientation

77 of the basis vectors chosen in GLP is consistent with the cell parameters for the standard setting of

78 the space group, although the ratios differ.

79 Twinning in chalcostibite was reported by Spencer (1896) based on axial ratio of Groth (1889), as

80 occurring on the (102) plane. The same twin was also listed by Hintze (1904, page 992), who used

81 Penfield's axial ratio. The twin plane is reported to coincide with the composition plane and, with

82 respect to the cell parameters obtained from the X-ray diffraction data, it becomes (104) in the

83 Pnma setting or (140) in the Pnam setting, after removing common factors remaining by adopting

84 the transformation. Palache et al. (1952) adopted basis vectors which correspond to the Pnam

85 setting of the space group; accordingly, the twin plane should have been indicated as (140).

86 Unfortunately, the Miller indices of the twin plane were taken directly from Hofmann (1933); in

87 other words, Palache et al. (1952) gave the axial ratio corresponding to the Pnam setting of the

88 space group, but the Miller indices corresponding to the Pnma setting. This error was replicated in a

89 few texts and databases where the twin is mentioned, for example mindat.org (entry No. 983 for

90 chalcostibite).

91 In our survey (Nespolo and Ferraris, 2009), based on the data reported by Palache et al. (1952),

92 assuming that the indexing was consistent with the axial ratio, we exchanged the $k$ and $l$ indices

93 when computing the twin lattice. The very large effective twin index was the result of the incorrect

94 indexing of the twin plane in Palache et al. (1952). After discovering this error, we repeated the

95 calculations and we report the correct results here. 


\section{Reticular analysis of the (104) twin in chalcostibite}

97 As we have shown in the previous section, the twin and composition plane reported by Hintze 98 (1904) has Miller indices (140) in the Pnam setting reported by Palache et al., and (104) in the 99 standard Pnma setting. On the basis of the cell parameters reported by Razmara et al. (1997) for

100 Pnma, namely $a=6.0160(1), b=3.7968(6), c=14.499(3) \AA$, two concurrent sublattices are based 101 on the twin plane, with quasi-perpendicular directions [302] (index 11, obliquity $0.83^{\circ}$ ) and [403] 102 (index 8, obliquity $2.12^{\circ}$ ), which lead to an effective twin index $n_{\mathrm{E}}=5.5$, as shown in Fig. 1 103 (calculations performed with the software geminography: Nespolo and Ferraris, 2006). This result 104 shows that (104) twin in chalcostibite is a normal, triperiodic hybrid twin; the large effective twin 105 index reported in our 2009 survey was the result of the error in the indexing of the twin plane in 106 Palache et al. (1952). The possibility of a diperiodic twin is therefore negated.

\section{Structural analysis of the (104) twin in chalcostibite}

108 Fig. 2 shows the structure of chalcostibite along the $\mathbf{b}$ axis (black: $\mathrm{Cu}$; grey: $\mathrm{Sb}$; white: $\mathrm{S}$ ) in the 109 cation-centred description. $\mathrm{Cu}$ has a slightly distorted tetrahedral coordination with $\mathrm{Cu}-\mathrm{S}$ bond lengths $2.2717,2 \times 2.3157$ and $2.3163 \AA$, whereas $\mathrm{Sb}$ has a more irregular coordination, in the shape

111 of a highly distorted tetragonal pyramid, with five bond distances at $2.4489,2 \times 2.5895$ and $1122 \times 3.1288 \AA$; the two longer distances barely contribute to the coordination of $\mathrm{Sb}$. Indeed, the 113 Effective COoordination Number (ECoN: Hoppe, 1979) for $\mathrm{Cu}$ and $\mathrm{Sb}$ is 3.99 for four $\mathrm{Cu}-\mathrm{S}$ bonds 114 and 3.36 for five Sb-S bonds, showing that the coordination for Sb is much more distorted than for $115 \mathrm{Cu}$ and is more realistically described a $3+2$. In the anion-centred description (Fig. 3), one $\mathrm{S}$ (S1) is coordinated by two $\mathrm{Cu}$, both at $2.3157 \AA$, and three $\mathrm{Sb}$, at 2.4489 and $2 \times 3.1288 \AA$; again, the two longer distances $\mathrm{S}-\mathrm{Sb}$ are borderline bond contacts. The other $\mathrm{S}(\mathrm{S} 2)$ is coordinated by two $\mathrm{Cu}$ at 
119 CHARDI2015: Nespolo and Guillot, 2016). The structure of minerals is commonly described as

120 based on cation-centred polyhedra, but the importance of the alternative interpretation as anion-

121 centred polyhedra has been repeatedly emphasized (see, e.g., Krivovichev et al., 2013; Beck, 2014;

122 Eon and Nespolo, 2015). As it was already pointed out by Hofmann (1933), both types of metal

123 atoms are very close to the (104) plane (Fig. 4); their position should therefore not be largely

124 affected by twinning. These atoms are located at at the corners of the coordination polyhedra in the

125 anion-centred description of the structure, which makes the visual comparison of the changes in

126 coordination due to twinning easier. The anion-centred description is therefore privileged below; the

127 cation-centred description leads to the same conclusions and is briefly presented in the discussion.

128 Hofmann (1933) did not provide any quantitative estimation of the perturbation the structure

129 undergoes at the formation of the twin. To obtain such a quantitative measure, we need to analyse

130 the pseudo-eigensymmetry of the crystallographic orbits, to find whether it contains an operation

131 whose linear part coincides with the twin operation. The approach has been described in details in

132 our previous articles, where the reader can find all the details; here we give just a brief summary.

133 The same approach has allowed us to explain the formation of twins in a number of minerals,

134 namely melilite (Marzouki et al. 2014a), staurolite (Marzouki et al. 2014b), aragonite (Marzouki et

135 al., 2015), marcasite (Nespolo and Souvignier, 2015a), cassiterite and rutile (Nespolo and

136 Souvignier, 2015b), forsterite (Azevedo and Nespolo, 2017) and the Carlsbad twin in orthoclase

137 (Nespolo and Souvignier, 2017).

138 The unit cell of the twin lattice is defined by the (104) plane and the [302] direction quasi-

139 perpendicular to it. Because the twin is hybrid, more than one direction quasi-perpendicular to the

140 (104) plane could be chosen, each corresponding to a different sublattice: in this case, [302]

141 (obliquity $0.83^{\circ}$ ) and [403] (obliquity $2.12^{\circ}$ ). The former direction is chosen to describe the

142 structure of chalcostibite in the setting of the twin, because of the lower obliquity, which allows a 


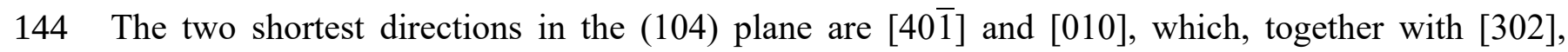
145 constitute the columns of the transformation matrix from the basis vectors $(\mathbf{a b c})_{\mathrm{I}}$ of the untwinned 146 chalcostibite to those of the twin $(\mathbf{a b c})_{\mathrm{T}}(\mathrm{I}=$ individual, $\mathrm{T}=$ twin $)$ :

$$
\left(\begin{array}{lll}
\mathbf{a} & \mathbf{b} & \mathbf{c}
\end{array}\right)_{\mathrm{I}}\left(\begin{array}{ccc}
4 & 0 & 3 \\
0 & 1 & 0 \\
1 & 0 & 2
\end{array}\right)=\left(\begin{array}{lll}
\mathbf{a} & \mathbf{b} & \mathbf{c}
\end{array}\right)_{\mathrm{T}}
$$

147 i.e. $\mathbf{a}_{\mathrm{T}} \mathbf{b}_{\mathrm{T}} \mathbf{c}_{\mathrm{T}}=4 \mathbf{a}_{\mathrm{I}}-\mathbf{c}_{\mathrm{I}}, \mathbf{b}_{\mathrm{I}}, 3 \mathbf{a}_{\mathrm{I}}+2 \mathbf{c}_{\mathrm{I}}$. The cell parameters of the twin lattice are $a_{\mathrm{T}}=28.094, b_{\mathrm{T}}=3.797, c_{\mathrm{T}}$ $148=34.156 \AA, \beta_{\mathrm{T}}=89.17^{\circ}$; the unit cell of the twin lattice is primitive, monoclinic but pseudo149 orthorhombic, with a deviation of $\beta$ which corresponds precisely to the obliquity and is eleven times 150 larger than the unit cell of the individual (this correspond to the index of the first sublattice); it 151 contains $16 \times 11=176$ atoms. The highest subgroup of Pnma compatible with this lattice is 152 obtained as $\mathcal{H}=G_{1} \cap G_{2}$ where $G_{1}$ and $G_{2}$ are the space groups of the two individuals, both of type $153 P$ Pnma, in the respective orientations. In our case, $\mathcal{H}$ is of type $P 2_{1} / m$. The fractional coordinates of 154 chalcostibite in the asymmetric unit of Pnma are given in Table 1. The Wyckoff splitting scheme to 155 the setting of the twin lattice is very simple: $4 c \rightarrow 22 \times 2 e$. Table 2 [Note that Table 2 is deposited, not printed, and freely available as Supplementary Material linked to this article on the GSW website of the journal: http://eurjmin.geoscienceworld.org/] gives the 88 atoms in the asymmetric unit of $P 2_{1} / m$. Crystallographic orbits having a (pseudo)-eigensymmetry containing a mirror or glide plane perpendicular to the $\mathbf{c}$ vector of the twin lattice are (quasi)-restored by the corresponding operation. In the cell of the twin lattice, there are 11 positions for the (001) plane passing on or close to the metal atoms, about $3.1 \AA$ apart. The eigensymmetry analysis can be performed about any of these positions: we take the one about $z=0.5$. The position of the metal atoms about $z=0.5$ are pseudosymmetric with respect to two orthorhombic minimal (index 2) supergroups of $P 2_{1} / \mathrm{m}$ : 
164 Pmmn (No. 59), with the basis vector in common with the individual, and Pbmm, which corresponds to Pmma (No. 51) expressed in a non-standard setting obtained with basis vector transformation $\mathbf{c}, \mathbf{a}, \mathbf{b}$. Table 3 gives the fractional atomic coordinates of the four independent metal atoms (the other four are obtained by applying an inversion), as well as the corresponding fractional

168 atomic coordinates obtained by applying an $n$-glide reflection (for Pmmn pseudo-eigensymmetry) 169 and a mirror reflection (for Pbmm pseudo-eigensymmetry), both about $z=0.5$. The Sb atoms are 170 restored by this operation within, respectively, $0.2625 \AA$ and $0.2732 \AA$, the $\mathrm{Cu}$ atoms within 0.3849 $171 \AA$ and $0.3825 \AA$. This means that if a change of orientation occurs during the crystal growth at $z=$ 1720.5 (with respect to the unit cell of the twin lattice), only a small adjustment of the metal atoms is 173 necessary to overcome this perturbation. The two candidate restoration operations corresponding to 174 the two pseudo-eigensymmetries do not lead, however, to the same coordination environment on the 175 two sides of the twin plane. The situation is shown in Fig. 5, where the region around $z=0.5$ is 176 shown for the untwinned crystal (bottom), the twinned model in Pmmn (middle), and the twinned 177 model in Pbmm (top). The position of the metal atoms on the twin plan being slightly different in 178 the two individuals, they are shown as split, almost overlapped atoms in the twinned models in Fig. 179 5. The coordination polyhedra share edges on the twin plane in the Pmmn model, as in the untwinned crystal, whereas they share faces in the Pbmm model. Twinning by reflection on (104) requires therefore a small adjustment of the metal atoms to produce a local structure at the boundary which is close to that of the untwinned crystal if the restoration operation is an $n$-glide; if instead the restoration operation is a mirror reflection, the coordination that results highly modified, an event which would make the twin less likely to occur.

185 Now, exactly the same conclusion can be drawn for the eleven positions of the twin plan every $\sim 3.1 \AA$. This means that during the crystal growth, twinning on (104) can be accommodated every $\sim 3.1 \AA$, making this twinning a relatively high probability event. 


\section{Discussion}

189 Fig 6 is obtained from the Pmmn twin model by taking the arithmetic average of the fractional coordinates of the metal atoms almost overlapped in the Fig. 5 (middle). The coordination polyhedra are essentially the same as those occurring in the untwinned mineral, but the S-metal distances are in some cases severely affected, resulting in some polyhedra of unphysically small

193 size, with some S-metal distances as short at 1.6 A. Clearly, the structural adjustment has to extend

194 further from the composition plane in order for the S-metal distances to approach their normal 195 values. From the energetic viewpoint, it is certainly more favourable if the strain occurring at the composition plane is absorbed through smaller deformations on a slightly wider region than a single larger deformation at the composition plane.

Fig. 7 is the cation-centred description of the structure of chalcostibite analogous to Fig. 5. The coordination polyhedra at the twin plane for the Pmmn model are essentially the same as those in the untwinned crystal, with the exception of one $\mathrm{Cu}$ site; here, one $\mathrm{S}$ has moved closer and another one farther from $\mathrm{Cu}$, leading to a triangular instead of tetrahedral coordination. The structural adjustment close to the twin plane mentioned above would easily restore the normal coordination of this $\mathrm{Cu}$ atom. In the Pbmm model, instead, the coordination at the twin plane is so heavily affected that it would require extensive rearrangements to get closer to the normal coordination in the bulk of the crystal. The Pmmn model is definitely more sound than the Pbmm model and the restoration operation for this twin is an $n$-glide perpendicular to the $\mathrm{c}$ axis of the twin lattice. The determination of the extent and extension of the structural adjustment around the twin plane would require a high-resolution transmission electron microscopy study of (104) twin in chalcostibite, which, to the best of our knowledge, has never been performed. With this study, we hope to draw the attention of electron microscopists on the interest to perform such an investigation. 
Acknowlegments. We thank Prof. Dominik Schaniel (CRM2, Université de Lorraine) for help with the German literature. Critical remarks from two anonymous reviewers and the Associate Editor are thankfully acknowledged.

\section{References}

Azevedo, S., Nespolo, M. (2017): Twinning in olivine group revisited. Eur. J. Mineral. 29, 213-226. Beck, H. P. (2014): The co-ordination number rule and the rule of hardness, powerful tools to rationalize inorganic structures. Z. Kristallogr. 229, 473-488.

Cervelle, B.D., Cesbron, F.P., Sichère, M.-C. (1979). La chalcostibite et la dadsonite de Saint-Pons, Alpes de Haute Provence, France. Can. Mineral. 17, 601-605.

Cumenge, M.E. (1879). Note sur une nouvelle espèce minérale découverte dans le district de Guejar, Sierra-Nevada (Andalousie). Bull. soc. min. 2, 201-203.

Eon, J.G. and Nespolo, M. (2015): Charge distribution as a tool to investigate structural details. III. Extension to description in terms of anion-centred polyhedra. Acta Crystallogr. B71, 34-47.

Friedel, C. (1879): Sur le forme cristalline de la Guejarite. Bull.soc. Minér. 2, 203-204.

Friedel, G. (1933): Sur un nouveau type de macles. Bull. Soc. franç Minér. 56, 262-274.

Glocker, E.F. von (1847): Generum et Specierum Mineralium Secundum Ordines Naturales digestorum Synopsis, Halle: E. Anton, 348 pp.

Goldschmidt, V. M. (1923). Atlas der Krystallformen, 9, 91. Heidelberg: Winter.

Groth, P. H. v. (1889): Tabellarische Übersicht der Mineralien nach ihren krystallographischchemischen Beziehungen. $3^{\text {rd }}$ edition, Braunschweig: F. Vieweg. X+167 pp.

Hintze, C. (1904): Handbuch der Mineralogie. Erster Band. Leipzig, Verlag von Veit \& Comp. $\mathrm{VI}+1208 \mathrm{pp}$.

Hofmann, W. (1933): Strukturelle und morphologische Zusammenhänge bei Erzen vom Formeltyp ABC2. Z. Kristallogr. 84, 177-203.

Hoppe, R. (1979): Effective coordination numbers (ECoN) and mean fictive ionic radii (MEFIR). Z. Kristallogr. 150, 23-52.

Huot, J.J.N. (1841). Nouveau manuel complet de minéralogie, ou tableau de toutes les substances minérales. Vol. I. Paris, La librarie encyclopédique de Roret, 402 pp.

Krivovichev, S.V., Mentré O.,Siidra, O.I., Colmont, M. and Filatov, S. K. (2013): Anion-Centered Tetrahedra in Inorganic Compounds. Chem. Rev. 113, 6459-6535.

Laspeyres, H. (1891): Mittheilungen aus dem mineralogischen Museum der Universität Bonn. Iv. Theil. Z. Kristallogr. 19, 417-436.

Marzouki, M.-A., Souvignier, B. \& Nespolo, M. (2014a): Analysis of the structural continuity in twinned crystals in terms of pseudo-eigensymmetry of crystallographic orbits. IUCrJ, 1, 3948.

—, —, - (2014b): The staurolite enigma solved. Acta Crystallogr., A70, 348-353.

- - - - (2015): Twinning of aragonite - the crystallographic orbit and sectional layer group approach. Acta Crystallogr., A71, 195-202.

Momma, K., Izumi, F. (2011): VESTA 3 for three-dimensional visualization of crystal, volumetric and morphology data. J. Appl. Crystallogr., 44, 1272-1276.

Nespolo, Ma., Aroyo, M.I. (2016): The crystallographic chameleon: when space groups change skin. Acta Crystallogr. A72, 523-538.

Nespolo, M., Ferraris, G. (2005): Hybrid twinning - A cooperative type of oriented crystal association. Z. Kristallogr. 220, 317-323.

-, - (2006): The derivation of twin laws in non-merohedric twins - Application to the analysis of hybrid twins. Acta Crystallogr. A62, 336-349. 
—, - (2009): A survey of hybrid twins in non-silicate minerals. Eur. J. Mineral. 21, 673-690.

258 Nespolo, M., Ferraris, G., Takeda, H., Takéuchi, Y. (1999): Plesiotwinning: oriented crystal associations based on a large coincidence-site lattice. Z. Kristallogr., 214, 378-382.

Nespolo, M., Guillot, B (2016): CHARDI2015: Charge Distribution analysis of non-molecular structures. J. Appl. Crystallogr., 49, 317-321.

Nespolo, M., Souvignier B (2015a): Application of the crystallographic orbit analysis to the study of twinned crystals. The example of marcasite. Cryst. Res. Techn,. 50, 442-450.

-, - (2015b): Structural rationale for the occurrence of the elbow twins in cassiterite and rutile. $J$. Mineral. Petrol. Sci., 110, 157-165.

-, - (2017): Structural analysis of twins in feldspars. I. Carlsbad twinning. Eur. J. Mineral. 29, in press (10.1127/ejm/2017/0029-2678).

Nicol, J. (1849): Manual of Mineralogy. Edinburgh : A. and C. Black, xxiv +576 pp.

Palache, C., Berman, H., Frondel, C. (1952): The system of mineralogy of James Dana and Edward Salisbury Dana', Vol. I, 7th ed., third printing, Wiley, New York and Chapman, London.

Penfield, S.L., Frenzel, A. (1897): Identity of Chalcostibite (Wolfsbergite) and Gruejarite, and on Chalcostibite from Huanchaca, Bolivia. Am. J. Sci. 4, 27-35.

Penfield, S.L., Frenzel, A. (1898): Ueber die Identität des Chalkostibit (Wolfsbergit) mit Guejarit und über Chalkostibit von Huanchaca, Bolivia. Z. Kristallogr. 28, 598-609.

Razmara, M.F., Henderson, C.M.B., Pattrick, R.A.D. (1997): The crystal chemistry of the solid solution series between chalcostibite $\left(\mathrm{CuSbS}_{2}\right)$ and emplectite $\left(\mathrm{CuBiS}_{2}\right)$. Mineral. Mag., 61, 79-88.

Spencer, L.J. (1896): Zinckenite and Wolfsbergite (Chalcostibite) from Wofsberg in the Harz; and the Zinckenite Group. Miner. Mag. 11, 188-191.

Ungemach, M. H. (1923): VIII. Sur les formes cristallines de notation compliquée. Z. Kristallogr. 58, $150-171$.

Zincken, C. (1835): Ueber den Kupfer-Antimonglanz, eine neue Mineralgattung. Aus einem Schreiben an den Prof. H. Rose in Berlin. Poggen. Ann. Phys. Chemie 35: 357-361. 
285 Figure 1. The lattice of chalcostibite projected along the [010] direction. drawn in scale according to the cell parameters reported by Razmara et al. (1997). Four-pointed and five-pointed black stars indicate lattice nodes belonging to the [302]/(104) and [403]/(104) sublattice respectively; nodes on the (104) plane are common the two two sublattice and indicated by black circle; white circles stand for lattice nodes not belonging to either of the sublattices. The unit cell based on the [302]/(104) pair of lattice elements has multiplicity 11 and contains one lattice node for each sublattice, so that the effective twin index is $11 / 2=5.5$.

Figure 2. The structure of chalcostibite observed down the $\mathbf{b}$ axis in the cation-centred description. $\mathrm{Cu}$ atoms occupy a distorted tetrahedron whereas $\mathrm{Sb}$ atoms are at the centre of a face of a distorted square pyramid (this and the following figures are drawn with VESTA: Momma and Izumi, 2011).

Figure 3. The structure of chalcostibite observed down the $b$ axis in the anion-centred description. The two crystallographically independent $\mathrm{S}$ atoms have different coordination: a $2 \mathrm{Cu}+3 \mathrm{Sb}$ distorted square pyramid and a $2 \mathrm{Cu}+2 \mathrm{Sb}$ distorted tetrahedron.

Figure 4. The ball-and-stick description of the structure of chalcostibite, with the (104) plane drawn in grey at the position $z=0.5$. Metal atoms are positioned very close to this plane. $\mathrm{Cu}$ atoms are shown in black, $\mathrm{Sb}$ atoms in grey, $\mathrm{S}$ atoms in white.

Figure 5. A portion of the structure of chalcostibite in the axial setting of the twin, drawn around the twin plane in the anion-centred description. Bottom: the untwinned structure. Middle: the Pmmn twinned model (the portion above the twin plane is obtained from the one below it by an $n$-glide reflection at $z=0.5$ ). Top: the $P b m m$ twinned model (the portion above the twin plane is obtained from the one below it by a mirror reflection at $z=0.5$ ). In both twinned models, the metal atoms close to the twin plane are shown in the positions corresponding to the two individuals; these positions being very close, the corresponding atoms are almost overlapped in the figure. Whereas in the Pnnm model the coordination polyhedra on the opposite sides of the twin plane share their edges, as in the untwinned crystal, in the Pbmm model they share their faces, leading to a physically unlikely situation.

Fig. 6. A likely structural adjustment at the composition plane, obtained by taking the arithmetic average of the fractional atomic coordinates of the metal atoms quasi-overlapped in Fig. 5. The Smetal coordination appears very similar to that in the untwinned crystal but actually some of the polyhedra have unphysically small volumes, indicating that the structural adjustment likely extends for a few atomic planes in order to minimize the structural strain occurring when the twin forms.

Figure 7. A portion of the structure of chalcostibite in the axial setting of the twin, drawn around the twin plane in the cation-centred description. Bottom: the untwinned structure; middle: the Pmmn twinned model; top: the Pbmm twinned model (same conventions as in Fig. 5). The positions of the $\mathrm{Cu}$ and $\mathrm{Sb}$ atoms on the twin plane are the arithmetic average of the positions in the two individuals; no other structural adjustment is introduced. In the Pnnm model, the coordination polyhedra are essentially the same as in the untwinned crystal, with the exception of one of the $\mathrm{Cu}$ sites; in the Pbmm model, instead, the coordination around the twin plane is severely affected. A structural adjustment of the $\mathrm{S}$ atoms close to the twin plane can restore the normal coordination in the Pmmn model but not in the Pbmm model. 
325 326

Table 1. Fractional atomic coordinates in the asymmetric unit of chalcostibite, setting Pnma. All atoms are in Wyckoff position 4c. Data from Ramzara et al (1997).

$$
\begin{array}{l|rrr}
\mathrm{Cu} & 0.7463(6) & 3 / 4 & 0.1721(2) \\
\mathrm{Sb} & 0.2245(2) & 1 / 4 & 0.0636(1) \\
\mathrm{S} 1 & 0.624(1) & 1 / 4 & 0.0960(4) \\
\mathrm{S} 2 & 0.131(2) & 3 / 4 & 0.1787(5)
\end{array}
$$

327 Table 3. Fractional atomic coordinates of metal atoms around $z=0.5$ (label without ') and after

\begin{tabular}{|c|c|c|c|c|c|c|c|c|c|c|c|}
\hline \multicolumn{12}{|c|}{ Pmmn } \\
\hline Atom & $x$ & $y$ & $z$ & Atom & $x$ & $y$ & $z$ & $\Delta x$ & $\Delta y$ & $\Delta z$ & $|\Delta|$ \\
\hline Sb11 & 0.93256 & 0.25 & 0.49808 & Sb18' & 0.94184 & 0.25 & 0.49728 & 0.00928 & 0 & 0.0008 & 0.2625 \\
\hline $\mathrm{Sb} 18$ & 0.44184 & 0.75 & 0.50272 & Sb11' & 0.43256 & 0.75 & 0.50192 & 0.00928 & 0 & 0.0008 & 0.2625 \\
\hline $\mathrm{Cu} 20$ & 0.68263 & 0.75 & 0.50526 & $\mathrm{Cu} 20^{\prime}$ & 0.68397 & 0.75 & 0.49406 & 0.00134 & 0 & 0.0112 & 0.3849 \\
\hline $\mathrm{Cu} 2$ & 0.18397 & 0.25 & 0.50594 & $\mathrm{Cu} 2^{\prime}$ & 0.18263 & 0.25 & 0.49474 & 0.00134 & 0 & 0.0112 & 0.3849 \\
\hline \multicolumn{12}{|c|}{ Pbmm } \\
\hline Atom & $x$ & $y$ & $z$ & Atom & $x$ & $y$ & Z & $\Delta x$ & $\Delta y$ & $\Delta z$ & $|\Delta|$ \\
\hline Sb11 & 0.93256 & 0.25 & 0.49808 & Sb11' & 0.93256 & 0.25 & 0.50192 & 0 & 0 & 0.0008 & 0.2732 \\
\hline Sb18 & 0.44184 & 0.75 & 0.50272 & Sb18' & 0.44184 & 0.75 & 0.49728 & 0 & 0 & 0.0008 & 0.2732 \\
\hline $\mathrm{Cu} 20$ & 0.68263 & 0.75 & 0.50526 & $\mathrm{Cu} 2^{\prime}$ & 0.68263 & 0.75 & 0.49474 & 0 & 0 & 0.0112 & 0.3825 \\
\hline $\mathrm{Cu} 2$ & 0.18397 & 0.25 & 0.50594 & $\mathrm{Cu} 02^{\prime}$ & 0.18397 & 0.25 & 0.49406 & 0 & 0 & 0.0112 & 0.3825 \\
\hline
\end{tabular}
328 application of a mirror reflection about $z=0.5$ label with '), in the two models Pmmn and Pbmm. 329 The difference is expressed both in terms of fractional atomic coordinated and in $\AA(|\Delta|)$. 


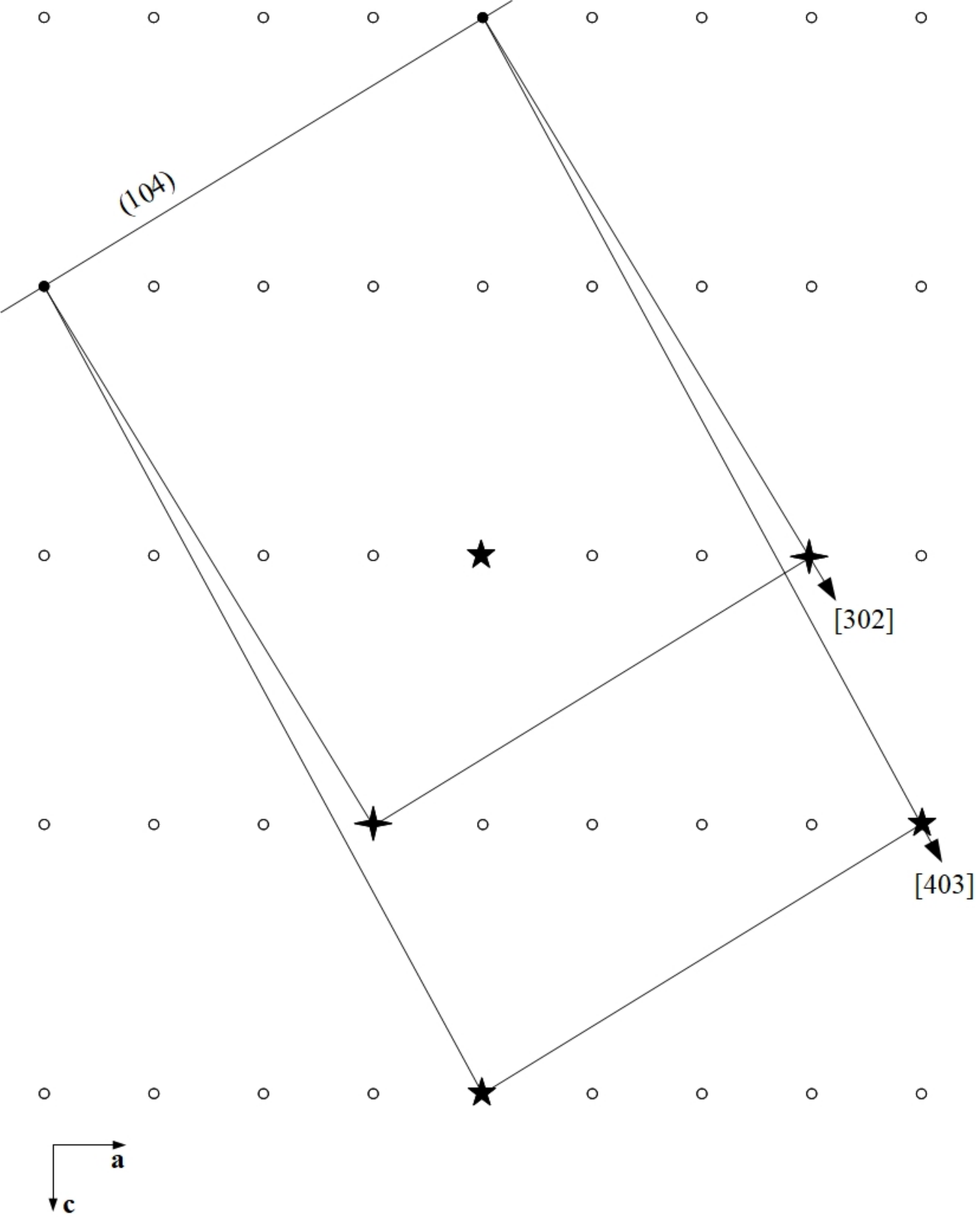




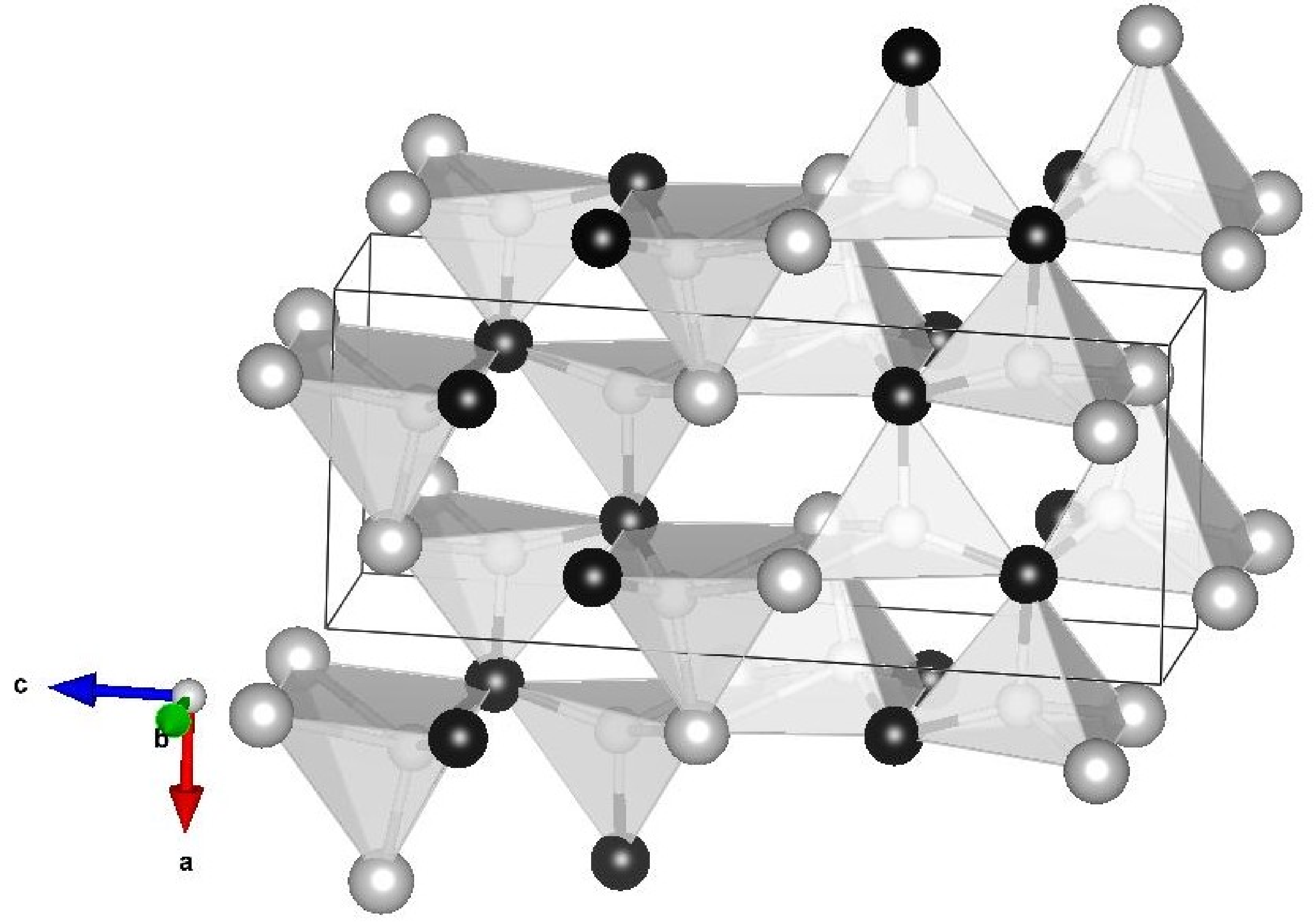




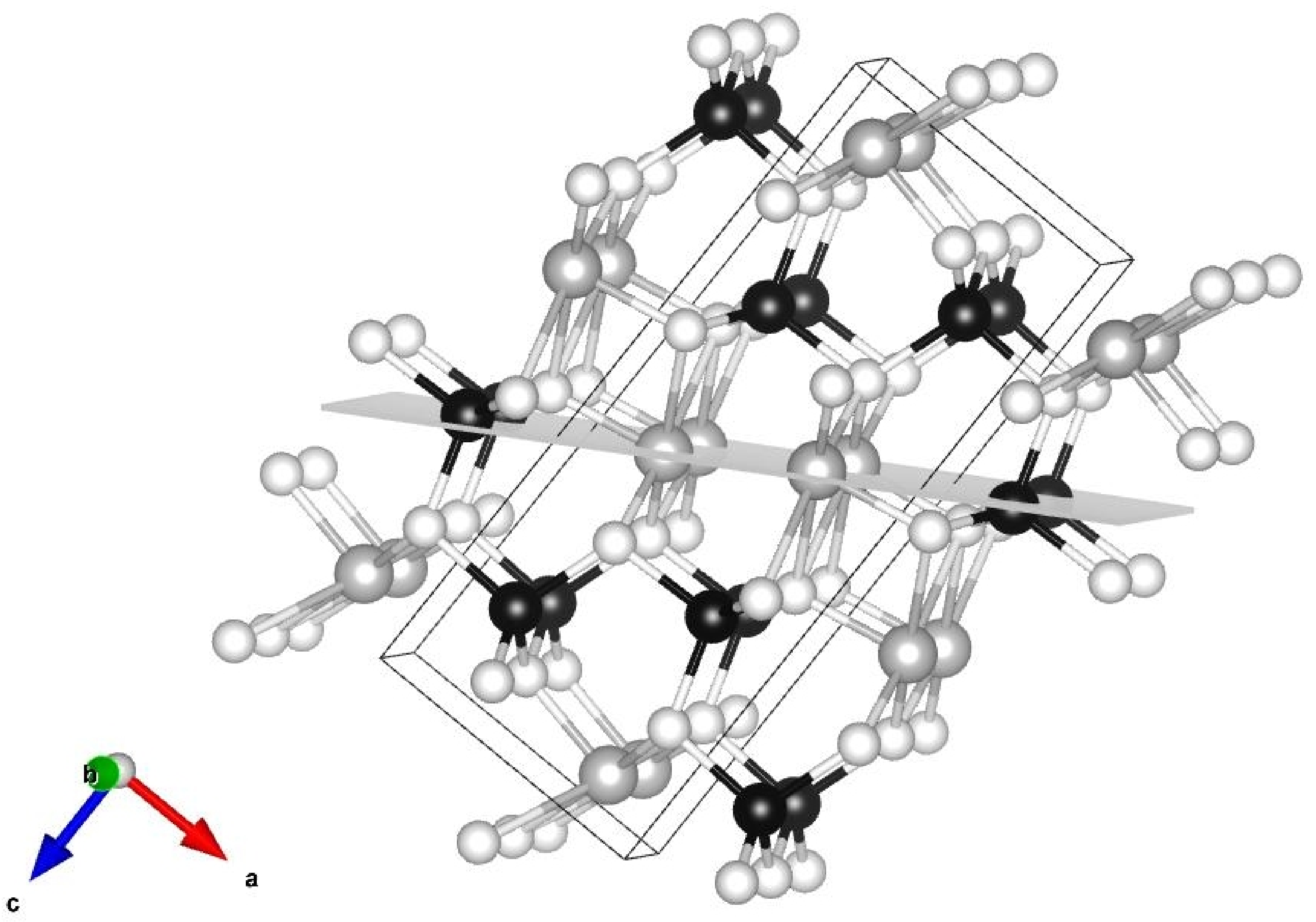




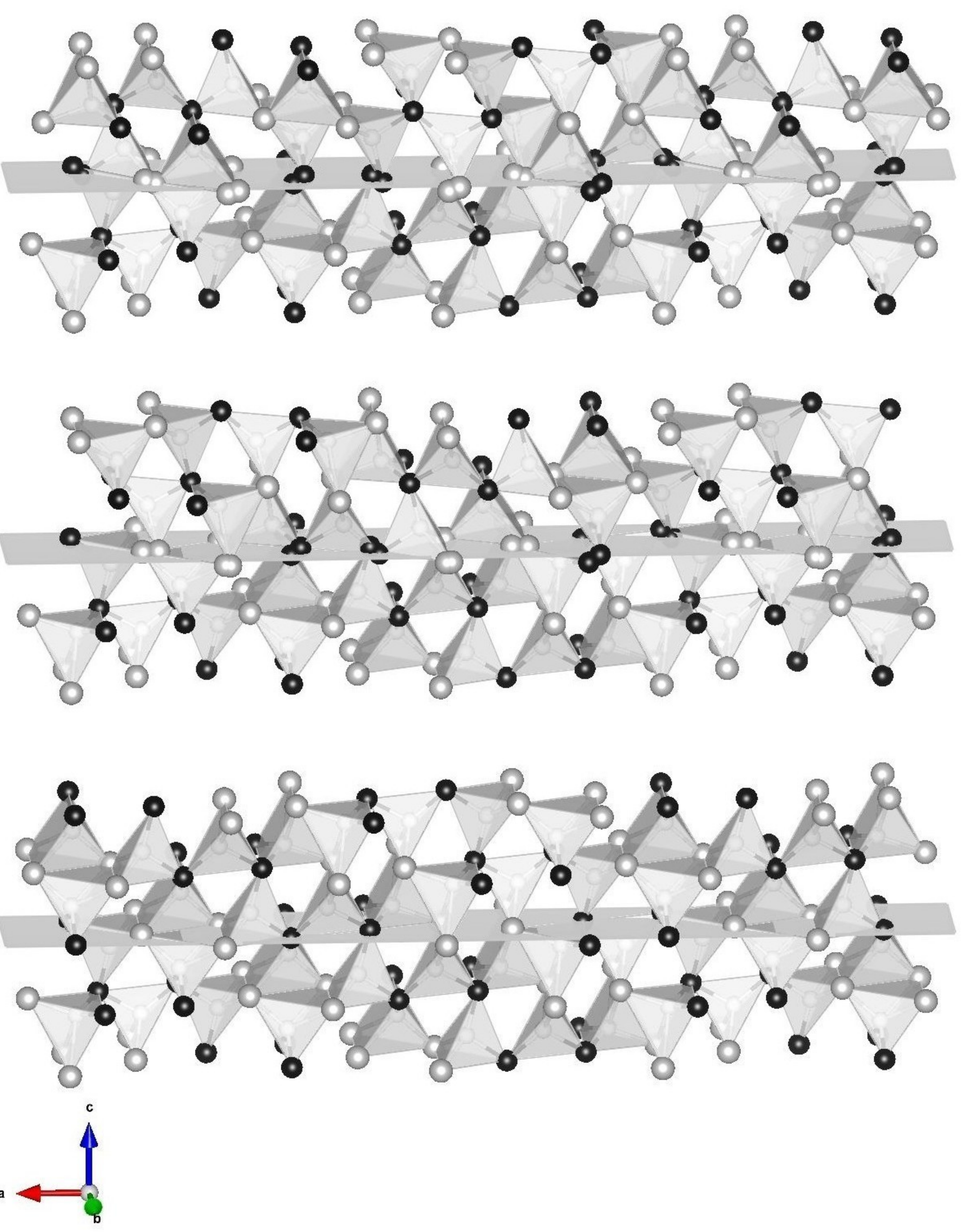




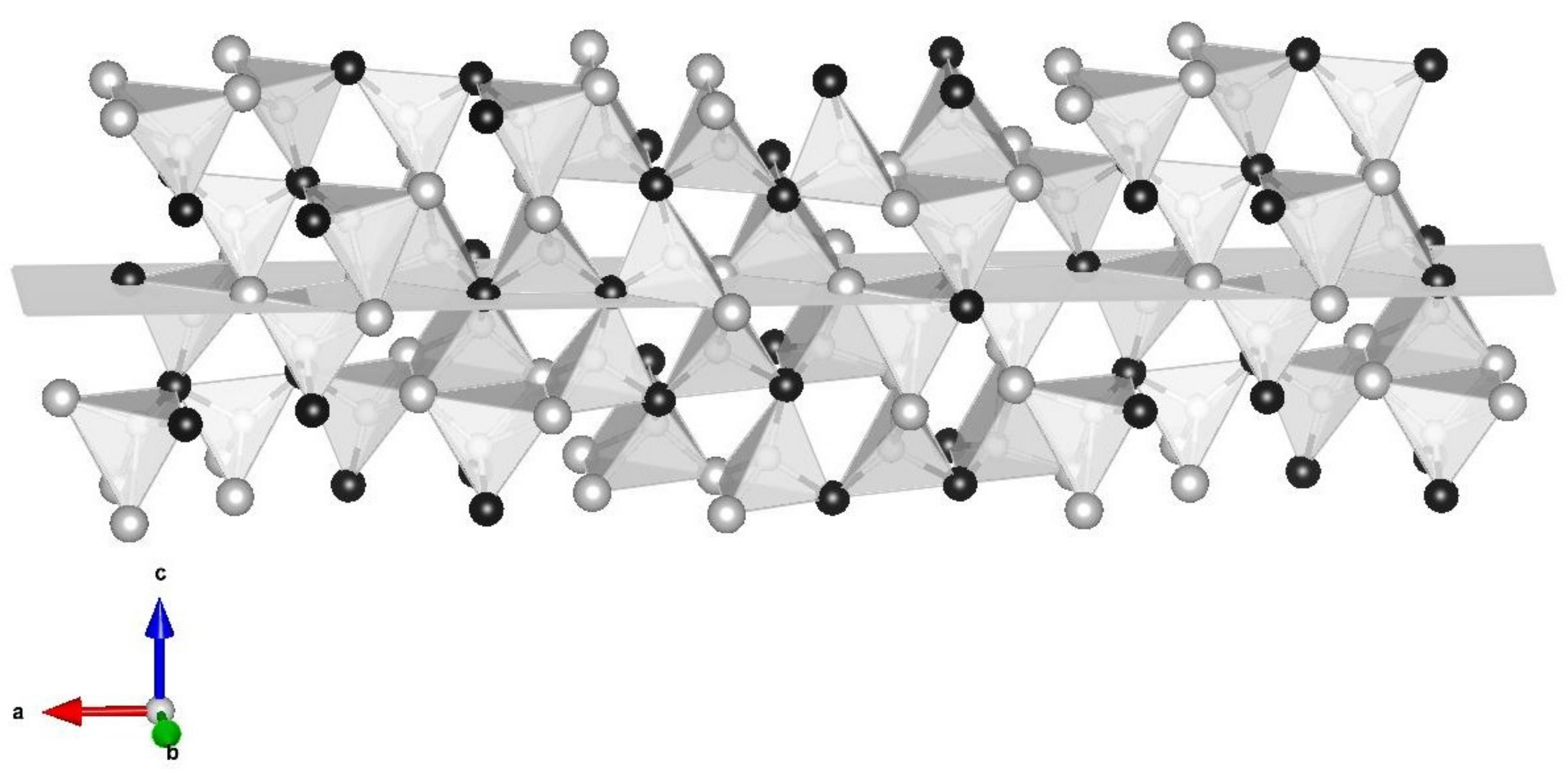




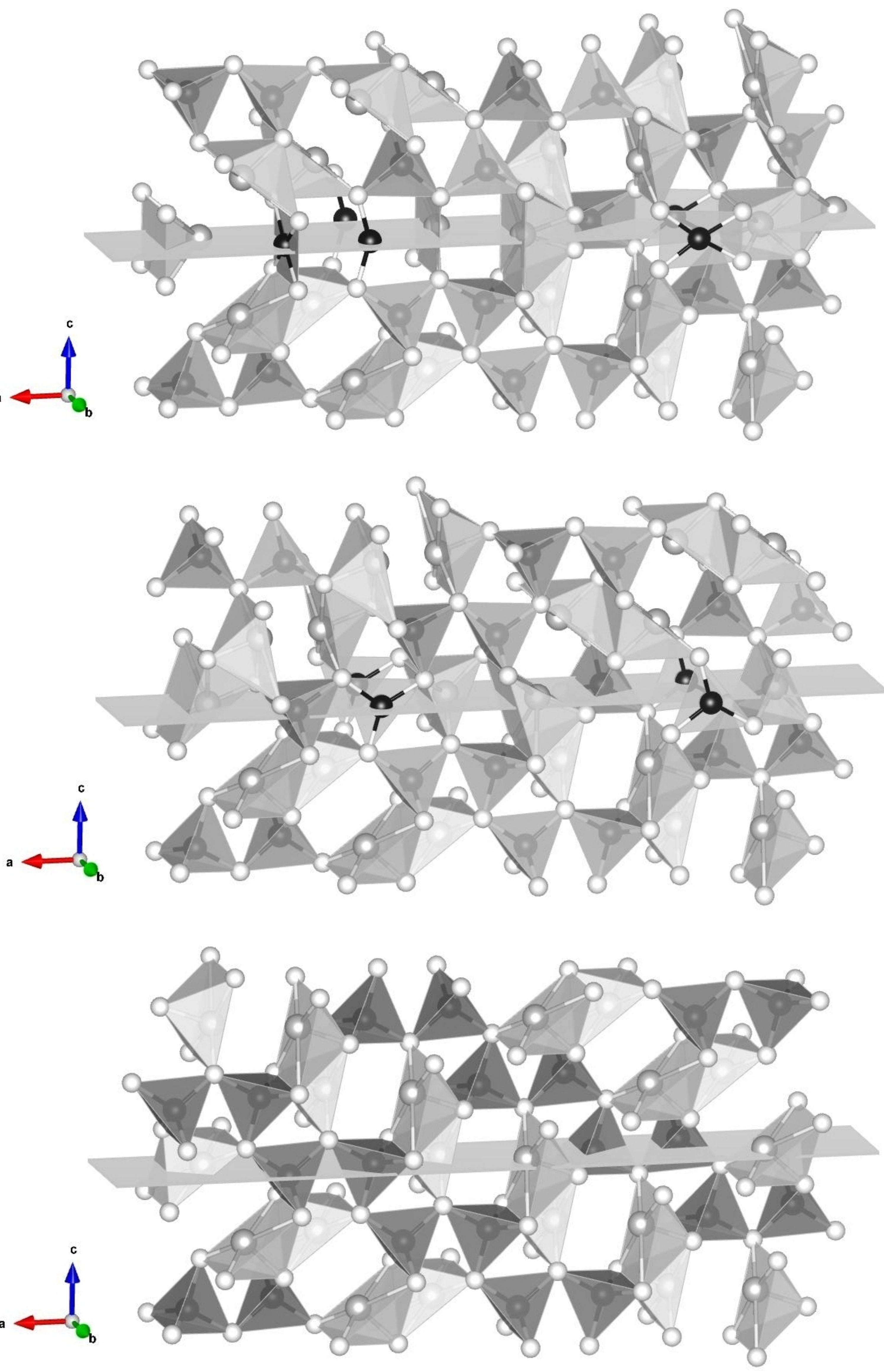

